\title{
Complicações pós-operatórias em pacientes submetidos a transplante renal: uma revisão narrativa
}

\author{
Postoperative complications in patients undergoing kidney transplantation: a narrative \\ review
}

Complicaciones postoperatorias en pacientes sometidos a trasplante renal: una revisión narrativa

Ana Carolline Oliveira Torres ${ }^{1 *}$, Bárbara Helena dos Santos Neves ${ }^{2}$, Brenda Karoline Lembi ${ }^{3}$, Carlos Eduardo da Silva Isidoro ${ }^{4}$, Fernanda Pimenta Fernandes ${ }^{5}$, Gabryelly Thallya Queiroz Oliveira ${ }^{6}$, Isadora de Castro Fischer ${ }^{7}$, Marina Ramos França Batista ${ }^{8}$, Priscilla Cristina Rodrigues de Lanas $^{9}$, Mariana Nogueira Coutinho ${ }^{10}$.

\begin{abstract}
RESUMO
Objetivo: Identificar as principais complicações do pós-transplante renal em pacientes portadores de insuficiência renal crônica no Brasil. Revisão bibliográfica: $O$ estudo da terapia renal substitutiva, que avaliou a legislação brasileira, os métodos do Conselho Regional de Medicina e as complicações prevalentes, foi essencial para a melhora das informações sobre a qualidade de vida do paciente portador de insuficiência renal crônica, sendo o transplante renal a terapia mais completa, podendo ser realizada por doadores vivos e falecidos. No entanto, é um tratamento complexo que envolve complicações, imunológicas e infecciosas, as quais temos a intenção de revisar neste artigo. Considerações finais: As complicações pós-transplantes renais são decorrentes principalmente de rejeição, infecção e alterações vasculares. Elas têm uma relação íntima com as condições do receptor, do doador, tipo do transplante (doador vivo ou falecido) e com a imunossupressão utilizada. É importante que a equipe esteja atenta a todos os riscos para minimizar as complicações ou identificá-las precocemente.
\end{abstract}

Palavras-chave: Transplante de rim, Complicações pós-transplante, Doença renal crônica.

\begin{abstract}
Objective: Identify the main complications of post-kidney transplantation in patients with chronic renal failure in Brazil. Bibliographic review: The study of renal replacement therapy, which evaluated Brazilian legislation, the methods of the Regional Council of Medicine and the prevalent complications, was essential for improving information on the quality of life of patients with chronic renal failure, kidney transplantation being the most complete therapy, which can be performed by living and deceased donors. However, it is a complex treatment that involves complications, immunological and infectious, which we intend to review in this article. Final considerations: Complications after kidney transplantats are mainly due to rejection, infection and vascular changes. They have an intimate relationship with the conditions of the recipient, the donor, the type of transplant (living or deceased donor) and the immunosuppression used. It is important that the team is attentive to all risks to minimize complications or identify them early.
\end{abstract}

Keywords: Kidney transplantation, Pos-transplant complications, Chronic kidney disease.

1 Universidade do Planalto Central Apparecido dos Santos (UNICEPLAC), Brasília - DF.

*E-mail: anacarollinetorres@gmail.com

${ }^{2}$ Centro Universitário de Várzea Grande (UNIVAG), Várzea Grande - MT.

${ }^{3}$ Centro Universitário Integrado (CEI), Campo Mourão - PR.

${ }^{4}$ Universidade Cidade de São Paulo (UNICID), São Paulo - SP.

${ }^{5}$ Faculdade Ciências Médicas de Minas Gerais (FCMMG), Belo Horizonte - MG.

${ }^{6}$ Faculdade Unifimes (UF), Goiânia - GO.

7 Universidade Luterana do Brasil (ULBRA), Canoas - RS.

8 Universidade de Rio Verde (UNIRV), Formosa - GO.

9 Universidade Internacional Três Fronteiras (UNINTER), Ciudad del Este, Paraguai.

10 Universidade Federal de Alagoas (UFAL), Maceió - AL. 


\section{RESUMEN}

Objetivo: Identificar las principales complicaciones del postrasplante renal en pacientes con insuficiencia renal crónica en Brasil. Revisión bibliográfica: El estudio de la terapia sustitutiva renal, que evaluó la legislación brasileña, los métodos del Consejo Médico Regional y las complicaciones prevalentes, fue fundamental para mejorar la información sobre la calidad de vida de los pacientes con insuficiencia renal crónica, siendo el trasplante renal, siendo el trasplante renal el más terapia completa, que puede ser realizada por donantes vivos y fallecidos. Sin embargo, es un tratamiento complejo que conlleva complicaciones, inmunológicas e infecciosas, que pretendemos revisar en este artículo. Consideraciones finales: Las complicaciones posteriores al trasplante de riñón se deben principalmente al rechazo, la infección y los cambios vasculares. Tienen una íntima relación con las condiciones del receptor, el donante, el tipo de trasplante (donante vivo o fallecido) y la inmunosupresión utilizada. Es importante que el equipo esté atento a todos los riesgos para minimizar las complicaciones o identificarlas temprano.

Palabras clave: Trasplante de riñón, Complicaciones pos trasplante, Enfermedad renal crónica.

\section{INTRODUÇÃO}

A Doença Renal Crônica (DRC) é caracterizada pela presença de lesão renal (albuminúria $\geq 30 \mathrm{mg} / \mathrm{g}$ ) e perda progressiva da função dos rins, que acontece de maneira lenta, silenciosa e irreparável, por um período maior ou igual a três meses (JESUS NM, et al., 2019). A função renal é avaliada pela mensuração da taxa de filtração glomerular (TFG) que, quando inferior a $60 \mathrm{~mL} / \mathrm{min} / 1.73 \mathrm{~m} 2$, caracteriza a presença da DRC (PEREIRA ERS, et al., 2016). No estágio mais avançado da doença (estágio 5 - G5), é inferior a $15 \mathrm{ml} / \mathrm{min} / 1.73 \mathrm{~m}^{2}$ (CABRAL ALT, et. al., 2018). Neste estágio, faz-se necessário o início de uma terapia renal substitutiva (TRS) para elevar a sobrevida do paciente (GÓMEZ-SÁNCHEZ MA, et al., 2019). Esta inclui três modalidades: hemodiálise, diálise peritoneal e transplante renal (TIZO JM e MACEDO LC, 2015).

De acordo com o Ministério da Saúde, dentre os transplantes de órgãos, o transplante renal é o mais frequente no Brasil. Em 2019, por exemplo, ocorreram cerca de 6.323 transplantes renais (BRASIL, 2019). Ele é uma das melhores opções de TRS, pois quando ele é bem-sucedido promove melhora na qualidade de vida e na sobrevida do paciente (SANTOS WN, et al., 2016; GÓMEZ-SÁNCHEZ MA, et al., 2019; CABRAL ALT, et al., 2018).

O transplante renal pode ter três tipos de doador: vivo relacionado, vivo não relacionado e falecido. Isto influencia diretamente na sobrevida do enxerto. Entre esses, existem maiores vantagens ao se receber o rim de um doador vivo, pois este transplante está relacionado com a redução do tempo na fila de espera, com um tempo de cirurgia mais curto e menores chances de complicações infecciosas e imunológicas (SANTOS WN, et lá., 2016; GÓMEZ-SÁNCHEZ MA, et al., 2019).

Outras vantagens do transplante doador vivo, é o tempo pequeno de isquemia entre a retirada do rim do doador até ser implantado no receptor, visto que a cirurgia de retirada do rim doado ocorre concomitantemente a cirurgia do receptor (CRUZ MGS, et al, 2015). Quando o doador é vivo relacionado, ou seja, parente do receptor, as vantagens são ainda maiores, visto que a probabilidade de rejeição pós-transplante é a menor (SANTOS WN, et lá., 2016; GÓMEZ-SÁNCHEZ MA, et al., 2019).

No Brasil, a legislação permite a doação entre parentes até quarto grau no caso de doadores vivos, porém quando se refere a doadores falecidos, o receptor do órgão transplantado necessariamente precisa estar inscrito na lista única de receptores de rim de um estado e aguardar um órgão compatível e oriundo de indivíduos que vieram a óbito devido à morte encefálica (CRUZ MGS, et al, 2015).

A morte cerebral é confirmada após o seguimento dos métodos rigorosos do Conselho Federal de Medicina (CFM). Pacientes com morte cerebral que serão doadores de rim, não podem ter nenhuma doença renal ou doença que possa ser posteriormente transmitida ao receptor, como infecção pelo vírus da imunodeficiência humana (HIV). Para prosseguir com a doação também é necessária a permissão dos familiares e testes de compatibilidade entre doador e receptor da fila. A quantidade de receptores é proporcional à quantidade de rins do doador, exemplo: se possuir dois rins viáveis, eles serão alocados em dois receptores (CRUZ MGS, et al., 2015). 
O transplante renal de doador falecido está associado ao maior risco de complicações e, no Brasil, a maioria dos transplantes renais são desse tipo de doador. Nesses casos, o tempo de isquemia fria é maior e possui relação tanto com eventos infecciosos como com a função retardada do enxerto, a qual também está associada a maior risco de rejeição. Outrossim, outras complicações como hipovolemia, necrose tubular aguda, alterações vasculares e nefrotoxicidade por imunossupressores também ocorrem com mais frequência nesse tipo de doador (TIZO JM e MACEDO LC, 2015; STARCK E, et al., 2020; MAIA NJAB, 2017; SANTOS WN, et al., 2019; GÓMEZ-SÁNCHEZ e ÁNGELES ML, 2019; REQUIÃO-MOURA LR et al., 2015b).

Ademais, apesar de o transplante renal ser uma alternativa com inúmeros benefícios, com importante melhora na qualidade de vida do paciente, ele pode acarretar em complicações relevantes, sendo a rejeição pós-operatória do enxerto a mais comum. Esta rejeição pode ocorrer de forma hiperaguda, aguda, humoral ou crônica. Dessa forma, os imunossupressores são utilizados para a modulação da resposta imune dos receptores transplantados a fim de aumentar o tempo de vida tanto do enxerto quanto do receptor e, consequentemente, reduzir a probabilidade de ocorrer rejeição (CABRAL ALT, et al., 2018; TIZO JM e MACEDO LC, 2015).

Outra complicação comum, devido à modulação do sistema imunológico do receptor, é a infecção póstransplante. Esta representa a segunda causa de morte entre os pacientes portadores de IRC, sendo responsável por mais de 50\% das complicações (STARK E, et al., 2020).

Nesse sentido, percebe-se que todo o processo de transplante é complexo. Pois, trata-se de uma cirurgia, envolvendo vários aspectos éticos, imunológicos somados a condições específicas do doador e do receptor, e que ainda pode acarretar problemas pós-operatórios. Nesse contexto, esse estudo tem como objetivo analisar os achados relevantes da literatura atual, nos últimos cinco anos, sobre complicações do póstransplante renal.

\section{REVISÃO BIBLIOGRÁFICA}

\section{Doença renal crônica e transplante renal no Brasil}

A DRC é uma enfermidade frequente, a qual atinge cerca de 12 milhões de brasileiros e a cada ano esse número aumenta devido à melhora da expectativa de vida dos brasileiros que contribui para o aumento da prevalência de doenças crônicas como a hipertensão arterial sistêmica e diabetes mellitus, sendo essas as principais etiologias da DRC (XAVIER SU, 2018; TIZO JM e MACEDO LC, 2015; LORES JC, et al., 2019; JESUS NM, et al., 2019).

De acordo com o Registro Brasileiro de Transplantes (Dimensionamento dos Transplantes no Brasil e em cada estado 2013-2020), em 2019 dos 35 países avaliados, o Brasil foi o segundo país em número absoluto de transplante renal, com 6.417 transplantes, ficando atrás apenas dos EUA com 24.273. Ademais, de acordo com a mesma fonte, o número de transplantes vem crescendo a cada ano. Em 2011 foram realizados 4.982, em 2014, 5.661 e em 2019, 6.283, sendo a maioria de doadores falecidos (ASSOCIAÇÃO BRASILEIRA DE TRANSPLANTE DE ÓRGÃOS, 2019).

Segundo o Kidney Disease Improving Global Outcomes, KDIGO (2020), a DRC é classificada por estágios de acordo com a TFG (G1 - G5) e albuminúria (A1 - A3). Assim, quanto maior o estágio, pior o prognóstico e maior a probabilidade de o paciente necessitar de TRS. O KDIGO recomenda que todos os pacientes com DRC em estágio G4-G5, isto é, $T F G<30 \mathrm{~mL} / \mathrm{min} / 1.73 \mathrm{~m}^{2}$, em evolução para estágio de falência renal, sejam considerados para realização de transplante renal, independentemente de sua condição socioeconômica, sexo, identidade de gênero ou raça/etnia. Excetuam-se os pacientes com algumas condições específicas como: mieloma múltiplo, amiloidose primária com comprometimento extrarrenal significativo, cirrose descompensada (considerar transplante combinado de fígado-rim), doença pulmonar obstrutiva grave, doença cardíaca grave e doença neurodegenerativa central progressiva (KDIGO, 2020; PEREIRA ERS, et al., 2016). Sendo assim, devido à prevalência da DRC no Brasil e ao aumento crescente de transplantes renais, fazem-se necessários estudos que avaliem as complicações dessa modalidade de tratamento. 


\section{Imunologia do transplante}

Uma das funções do sistema imunológico é tanto o reconhecimento de substâncias e microrganismos estranhos que conseguiram entrar no organismo, como de antígenos próprios, os quais são tolerados por esse sistema (TIZO JM e MACEDO LC, 2015).

Após um transplante renal, o sistema imune percebe o rim como um objeto estranho, "não próprio" e, portanto, promove uma reação contra esse órgão. Isso pode resultar em dano ou até mesmo em perda do enxerto, processo denominado de rejeição. As moléculas do complexo principal de histocompatibilidade (MHC, "major histocompatibility complex") - Human Leukocyte Antigen (HLA) nos humanos - funcionam como receptores de antígenos oriundos do doador ou do enxerto, apresentando-os aos linfócitos $T$ do receptor e são as responsáveis por esse processo de rejeição (TIZO JM e MACEDO LC, 2015; STARCK E, et al., 2020; SANTOS WN, et al., 2019).

Os antígenos das moléculas de HLA são os principais alvos da rejeição do transplante, portanto, a minimização da diferença do HLA entre doador e receptor influencia na sobrevida do enxerto (MAIA NJAB, 2017). Os imunossupressores são prescritos com a finalidade de evitar essa complicação grave.

Entretanto, apesar de sua extrema importância, eles podem ocasionar diversos efeitos colaterais como nefrotoxicidade, hipertensão, dislipidemia e diabetes mellitus pós-transplante. Assim como podem favorecer o surgimento de infecções no período pós-transplante, principalmente nas primeiras semanas (TIZO JM e MACEDO LC, 2015; GALANTE NZ, 2015).

\section{Complicações prevalentes em pacientes com transplante renal}

Muitas complicações pós-transplante renal estão relacionadas com o tipo de doador. Quando se trata de doador vivo, há muitas vantagens para o receptor como supracitado. Entretanto, no Brasil, a maioria dos transplantes renais é de doadores falecidos, como visto em 2019, quando aproximadamente $83 \%$ dos transplantes foram deste tipo (TIZO JM e MACEDO LC, 2015; ASSOCIAÇÃO BRASILEIRA DE TRANSPLANTE DE ÓRGÃOS, 2018).

O maior risco de complicações decorrentes do transplante renal de doador falecido está associado, principalmente, ao maior tempo de isquemia fria, quando comparado aos doadores vivos. Esse tempo de isquemia é o tempo durante o qual o enxerto fica em hipotermia após ter sido retirado do doador até o momento de sua reperfusão no receptor, o que também causa lesões de isquemia-reperfusão. Estudos demonstram que a cada incremento de 30 minutos no tempo de isquemia fria aumenta-se o risco de infecção pós-transplante (TIZO JM e MACEDO LC, 2015; STARCK E, et al., 2020; MAIA NJAB, 2017; SANTOS WN, et al., 2019).

Ademais, o tempo de isquemia fria também está relacionado à outra complicação bastante comum em pacientes que receberam enxerto de doador falecido: a função retardada do enxerto (FRE), que é caracterizada pela necessidade de diálise na primeira semana após transplante. No Brasil, as taxas de FRE ficam em torno de 50 a $60 \%$, que está de acordo com a porcentagem de transplante oriundo de doador falecido. A FRE também está associada a maior risco de rejeição aguda, visto que há aumento da imunogenicidade do aloenxerto induzida por lesão de isquemia e reperfusão, o que aumenta a liberação de citocinas inflamatórias e a expressão de moléculas de MHC na superfície das células do enxerto. Além disso, a demora na recuperação da função do enxerto aumenta o tempo de internação, o que também contribui para ocorrência de infecção, culminando em pior sobrevida do enxerto a longo prazo (SANTOS WN, et al., 2019; LORES JC, et al., 2019; HELFER MS, et al., 2019).

A perda do enxerto pode ocorrer devido às complicações pós-transplante, principalmente aquelas que ocorrem na primeira semana. Entretanto, isso pode ser evitado quando identificadas precocemente (GÓMEZSÁNCHEZ MA e ÁNGELES ML, 2019). Dentre as complicações precoces, ou seja, aquelas que ocorrem nas primeiras 48 horas, as mais comuns são: hipovolemia, necrose tubular aguda (NTA), rejeição hiperaguda e aguda, nefrotoxicidade por inibidores da calcineurina da ciclosporina e oclusão vascular (GÓMEZ-SÁNCHEZ MA e ÁNGELES ML, 2019). 
A NTA é uma complicação consequente da isquemia fria do rim do doador e da lesão de reperfusão, sendo causa frequente de deterioração da função renal, sendo mais comum em doadores cadavéricos (GÓMEZSÁNCHEZ MA e ÁNGELES ML, 2019; REQUIÃO-MOURA LR, et al., 2015).

A Rejeição Hiperaguda, também conhecida como humoral, ocorre minutos ou horas após o transplante e é observada, geralmente, em transplantes em que o paciente apresenta sistema ABO incompatível com o enxerto ou crossmatch positivo. O Crossmatch, exame que determina a pré-existência de anticorpos do receptor contra as células do doador, é importante nesses casos, pois, quando testa positivo, interpreta 0 ataque das células receptoras às células do órgão transplantado (TIZO JM e MACEDO LC, 2015).

A rejeição aguda ocorre habitualmente de uma a três semanas após o transplante. Esta pode ser clinicamente percebida pela presença de febre, hipertensão arterial sistêmica, dor e edema sobre o enxerto, redução da diurese, função tardia do enxerto e aumento da creatinina sérica. Tem-se ainda a nefrotoxicidade devido ao uso de inibidores da calcineurina (ciclosporina ou tacrolimus), ela eventualmente ocorre, tornandose hemodinâmico-funcional, dose-dependente e reversível, afetando primordialmente vasos e túbulos, em razão de causar disfunção endotelial (GÓMEZ-SÁNCHEZ MA e ÁNGELES ML, 2019; TIZO JM e MACEDO LC, 2015).

Por fim, uma importante causa de disfunção do enxerto com alta morbidade e mortalidade associadas são as complicações vasculares. Merecem destaque duas condições: a trombose venosa do enxerto, identificada em menos de $5 \%$ dos pacientes na primeira semana e a estenose da artéria renal, uma etiologia para hipertensão arterial após o transplante e responsável pela alteração funcional do enxerto, com incidência variável entre 1 a $25 \%$. Além disso, pode ocorrer trombose segmentada da veia safena interna, com incidência em $3 \%$; trombose arterial do enxerto (3\%) e trombose venosa profunda do segmento femoral (2\%) (GÓMEZSÁNCHEZ MA e ÁNGELES ML, 2019; HABERAL M, 2016; ECKER R, et al., 2019).

\section{Infecção pós-transplante renal}

Na prática clínica do transplante renal, é evidente que grande parte dos receptores apresentam uma evolução positiva no período de recuperação. No entanto, estudos apontam que complicações infecciosas possuem uma prevalência elevada no primeiro ano após o recebimento do enxerto. Esse cenário associa-se a condições pré-existentes do indivíduo, mas, principalmente, ao seu estado de imunossupressão. Dessa forma, o período de permanência hospitalar e a qualidade do cuidado pós-operatório são considerados fatores de risco para as infecções. As complicações infecciosas válidas de se ressaltar são, principalmente, as relacionadas à infecção pelo citomegalovírus (CMV) e às infecções do trato urinário (ITU) (STARCK E, et al., 2020; MAIA NJAB, 2017; LEAL R, et al., 2017).

$A$ infecção pelo CMV destaca-se devido à sua prevalência pós-transplante. Esta pode ser classificada em primoinfecção, quando ocorre por meio do enxerto, ou em reativação, quando o receptor é soropositivo, de maneira que a doença se manifesta com um amplo espectro clínico: assintomático, síndrome viral ou doença invasiva (CHAN S, et al., 2019; FEHR T, et al., 2015).

Por este motivo, todos os candidatos a transplante de rim, bem como todos os doadores, devem avaliar seu status imunológico para o vírus, a partir da dosagem de anticorpos da classe lgG, pois o match sorológico entre o doador $(D)$ e o receptor $(R)$ pode ser considerado um marcador para o prognóstico. Assim, quando D+/R- são comparados com D-/R- há um aumento de $28 \%$ no risco de perda do enxerto do D+/R- (REQUIÃOMOURA LR, et al., 2015a). Ademais, estudos apontam que o CMV possui diversos efeitos imunomoduladores indiretos que contribuem para a ocorrência de rejeição aguda ou crônica após o transplante, além de provocar alterações vasculares crônicas que podem culminar na vasculopatia crônica no transplante de rim (FEHR T, et al., 2015).

Visando a redução da infecção pelo CMV, os pacientes considerados de alto risco (com match sorológico $\mathrm{D}+/ \mathrm{R}$ - ou que receberam algum tipo de anticorpos depletores de linfócitos) podem ser submetidos à profilaxia ou ao tratamento preemptivo. A profilaxia consiste em administração de antiviral (ganciclovir ou valganciclovir) entre um período de 3 a 6 meses, porém essa estratégia está relacionada ao risco de resistência à droga ou ao desenvolvimento da doença de início tardio. Já o tratamento preemptivo contempla a monitorização da 
viremia normalmente entre o $21^{\circ}$ e o $90^{\circ}$ dia pós-operatório, somado a administração de ganciclovir ou valganciclovir em pacientes com viremia positiva. Portanto, a monitorização e o diagnóstico (por antigenemia ou reação em cadeia de polimerase) são de suma relevância para identificar pacientes com potencial risco de evoluir de forma desfavorável após o transplante (REQUIÃO-MOURA LR, et al., 2015; CHAN S, et al., 2019).

A ITU é a infecção mais comum entre os receptores de rim e está associada ao aumento da morbimortalidade desses pacientes. Ela pode ocorrer em qualquer momento, porém sua maior incidência é observada no primeiro ano, mais especificamente nos 3 primeiros meses após o transplante (STARCK E, et al., 2020). A ocorrência de ITU determina o prognóstico e a evolução da recuperação pós-operatória, pois embora seu impacto na sobrevida do enxerto não seja completamente elucidado, é a causa mais comum de sepse em receptores de transplante renal. A contaminação se dá de forma variada, podendo ser causada por fatores relacionados ao hospedeiro, como imunossupressão e distúrbios urológicos, juntamente a fatores externos, como a presença de um ferimento, uso do cateter urinário ou até o próprio ambiente hospitalar (SCHIAVELLI R, et al., 2019).

É notório dizer que o trato urinário sofre diversas agressões durante o processo do transplante, seja na cirurgia, com a interrupção do seu curso normal, seja no pós-operatório com o uso do cateter vesical. Desta forma, é importante adotar estratégias para reduzir as chances de infecção. No que tange ao ambiente hospitalar, é imprescindível que a equipe de saúde esteja capacitada a realizar a técnica de forma correta, garantindo a antissepsia do procedimento. Além disso, é essencial que as instituições possuam os recursos necessários para fornecer o material para contemplar a segurança do profissional e do paciente. Com relação ao tempo de retirada da sonda vesical, não há consenso entre os centros de transplantes, porém estudos apontam que a redução do seu tempo de uso, isto é, retirar em um período de até sete dias, reduz o risco de infecções urinárias sem aumentar complicações urológicas (MAIA NJAB, 2017; SCHIAVELLI R, et al., 2019).

Nessa perspectiva, devido a anatomia do trato urinário inferior, o gênero feminino é considerado grupo de risco para as ITUs, pois as alterações anatômicas como o comprimento da uretra, sua localização próxima à abertura anal, dentre outros fatores, contribui para essa incidência. Outro ponto válido de destacar é que condições pré-existentes no receptor também aumentam a chance de ITU, como o diabetes mellitus, que está associado à neuropatia diabética, a qual pode acarretar alterações na sensibilidade, levando ao aumento do resíduo vesical e tornando o ambiente propício para a colonização bacteriana. Ademais, a hiperglicemia associada a essa patologia também contribui para infecção (STARCK E, et al., 2020).

Por fim, existem outros fatores relacionados às complicações infecciosas após o transplante renal como o tempo de cirurgia, a realização de transplantes concomitantes, a duração da internação e as condições de saúde do doador e do receptor. Portanto, sabendo-se da sua prevalência e da sua severidade, reforça-se a necessidade de que os profissionais de saúde estejam atentos às condições às quais o receptor será submetido, para que seja possível traçar o melhor plano terapêutico.

\section{CONSIDERAÇÕES FINAIS}

Nos últimos cinco anos, o avanço nas pesquisas nesta área teve papel fundamental para a análise de agravos no pós-transplante. As complicações imunológicas têm sido minimizadas com a qualidade dos imunossupressores, porém ainda é uma complicação frequente e que predispõe às complicações infecciosas. Apesar de todos os desafios envolvidos no cuidado deste paciente, ainda é o método de tratamento que proporciona a maior qualidade e expectativa de vida para o paciente renal crônico terminal. Conhecer, prevenir e identificar precocemente as complicações é determinante para o sucesso deste tratamento.

\section{REFERÊNCIAS}

1. ASSOCIAÇÃO BRASILEIRA DE TRANSPLANTE DE ÓRGÃOS. Registro Brasileiro de Transplantes. Dimensionamento dos Transplantes no Brasil e em cada estado (2013 - 2020).

2. BRASIL. Ministério da Saúde. Biblioteca Nacional em Saúde. Insuficiência renal crônica, 2015.

3. BRASIL. Ministério da Saúde. Doação de Órgãos: transplantes, lista de espera e como ser doador, 2019. 
4. CABRAL ALT, et al. As repercussões no estilo de vida e nas atividades laborais dos pacientes com doença renal crônica após o transplante renal. CIAIQ, 2018; 2.

5. CHAN S, et al. Infectious complications following kidney transplantation - A focus on Hepatitis C infection, Cytomegalovirus infection and novel developments in the gut microbiota. Medicina, 2019; 55(10): 672.

6. CRUZ MGS, et al. Vivência da família no processo de transplante de rim de doador vivo, $2015 ; 28$ (3): $275-280$.

7. ECKER R, et al. Mortalidade pós-transplante renal. Revista Interdisciplinar de Estudos em Saúde da UNIARP, 2019; 9(2): 253-260.

8. FEHR T, et al. Cytomegalovirus post kidney transplantation: prophylaxis versus pre-emptive therapy? Transplant International, 2015; 28(12): 1351-1356.

9. GALANTE NZ. Tratamento de indução no transplante renal. J Bras Nefrol.,2015; 37(2): 156-157.

10. GÓMEZ-SÁNCHEZ MA, ÁNGELES ML. Complicaciones de pacientes con trasplante renal en las primeras 48 horas en un hospital de tercer nivel de atención. Revista de Enfermería del Instituto Mexicano del Seguro Social, 2019; 27(3): 154-162.

11. HABERAL M, et al. Surgical Complications After Kidney Transplantation. Exp Clin Transplant., 2016; 14(6): 587-595.

12. HELFER MS, et al. Efeitos de longo prazo da duração da função tardia do enxerto sobre a função e sobrevida de transplantes renais com doadores falecidos. J. Bras. Nefrol., 2019; 41(2): 231-241.

13. JESUS NM, et al. Qualidade de vida de indivíduos com doença renal crônica em tratamento dialítico. J. Bras. Nefrol., 2019; 41(3): 364-374.

14. KIDNEY DISEASE IMPROVING GLOBAL OUTCOMES - KIDIGO. Clinical Practice Guideline on the Evaluation and Management of Candidates for Kidney Transplantation. Official Journal of The Transplantation Society, 2020; 104(4).

15. LEAL R, et al. Early Rehospitalization PosteKidney Transplant Due to Infectious Complications: Can We Predict the Patients at Risk? Transplantation Proceedings, 2017; 49(4): 783-786.

16. LORES JC, et al. Transplante renal: relacionando tipo de enxerto e tempo de isquemia. Rev enferm UFPE on line, 2019; 13(5): 1405-1411

17. MAIA NJAB. Tempo de Isquemia Fria e a Incidência de Complicações Infecciosas após o Transplante Renal. Dissertação (Mestrado em Medicina). Faculdade De Medicina da Universidade de Coimbra, Coimbra; 2017.

18. PEREIRA ERS, et al. Prevalência de doença renal crônica em adultos atendidos na Estratégia de Saúde da Família. J Bras Nefrol, 2016; 38(1): 22-30.

19. REQUIÃO-MOURA LR, et al. Infecção pelo Citomegalovírus no transplante de rim: aspectos clínicos, manejo e perspectivas. Einstein (São Paulo), 2015a; 13(1): 142-148.

20. REQUIÃO-MOURA LR, et al. Lesão de isquemia e reperfusão no transplante renal: paradigmas hemodinâmicos e imunológicos. Einstein (São Paulo), 2015b; 13(1): 129-135.

21. SANTOS WN, et al. Atuação do enfermeiro nas complicações decorrentes do transplante renal: uma revisão de literatura. Revista UNINGÁ Review, 2016; 25(1): 136-142.

22. SCHIAVELLI R, et al. Infecciones urinarias por microorganismos multirresistentes en pacientes transplantados renales internados. Rev Nefrol Dial Traspl. 2019; 39(1): 15-25.

23. STARCK E, et al. Complicações infecciosas no primeiro ano pós-transplante renal. Braz. J. of Develop., 2020; 6(6): 36663-36676.

24. TIZO JM, MACEDO LC. Principais complicações e efeitos colaterais pós-transplante renal. Revista UNINGÁ Review, $2015 ; 24(1): 62-70$.

25. WESTPHAL GA, et al. Diretrizes para avaliação e validação do potencial doador de órgãos em morte encefálica. Rev. bras. ter. intensiva, São Paulo, 2016; 283(3): 220-255.

26. XAVIER SU, et al. Na correnteza da vida: a descoberta da doença renal crônica. Interface (Botucatu), 2018; 22(66): 841-851. 